\title{
Structural changes of hexamethylenetetramine and undecanedioic acid co-crystal (HMT-C11) as a function of the temperature
}

\section{Carlos Basílio Pinheiro, Manuel Gardon and Gervais Chapuis}


Acta Crystallographica Section B

Structural

Science

ISSN 0108-7681

Carlos Basílio Pinheiro, ${ }^{\mathrm{a} *}$ Manuel Gardon $^{b}$ and Gervais Chapuis ${ }^{a}$

anstitut de Cristallographie, Université de Lausanne, BSP-Dorigny, CH-1015 Lausanne, Switzerland, and ${ }^{\mathbf{b}}$ Institut für Experimental Physik, Universität Wien, Strulhofgasse 4, A-1090 Wien, Austria

Correspondence e-mail: carlos.basilio@ic.unil.ch

\section{Structural changes of hexamethylenetetramine and undecanedioic acid co-crystal (HMT-C11) as a function of the temperature}

HMT-C11 belongs to the family of adducts formed by the cocrystallization of $\mathrm{N}_{4}\left(\mathrm{CH}_{2}\right)_{6}$ molecules (hexamethylenetetramine or HMT) and aliphatic dicarboxylic acids $\mathrm{HOOC}\left(\mathrm{CH}_{2}\right)_{n-2} \mathrm{COOH}$ with $5 \leq n \leq 13(\mathrm{Cn})$. The adducts exhibit a layered structure in which the packing between HMT and $\mathrm{Cn}$ is determined by strong hydrogen bonds. The compounds in this family studied so far present thermotropic structural phase transitions and, depending on the chain length, disordered, twinned and modulated phases. The structure refinement of HMT-C11 based on X-ray diffraction experiments indicates three distinct phases from the melting point down to liquid nitrogen temperature: phase $\mathrm{I}$ is not crystalline; phase II is disordered (stacking fault) and its average structure is described in space group $B m m b$; phase III is partially disordered and its symmetry is $P 2_{1} / c$. The systematic study of the structure evolution of phase III upon cooling revealed that the disorder has a dynamic character (anharmonicity). The main structural change observed from $293 \mathrm{~K}$ down to $93 \mathrm{~K}$ is the increase of the tilting angle of the $\mathrm{C} 11$ chains relative to the layer plane and the rotation of the HMT molecules. Both HMT and C11 behave like rigid bodies in the temperature range investigated. The quality of the refinements leads to a conclusive model for the $\mathrm{O}-\mathrm{H} \cdots \mathrm{N}$ hydrogen bonds linking HMT and C11.

\section{Introduction}

The crystal structure of the highly symmetric hexamethylenetetramine $\mathrm{N}_{4}\left(\mathrm{CH}_{2}\right)_{6}$ (HMT) molecule was determined by Dickinson \& Raymond (1923) at room temperature (RT). It crystallizes in the non-centrosymmetric cubic space group $I \overline{4} 3 \mathrm{~m}$ with the lattice parameter $a=7.028 \AA$. All the atoms occupy special positions. No thermotropic phase transition has been reported so far, however, Terpstra et al. (1993) and Kampermann et al. (1995) demonstrated an intrinsic anharmonicity in the $\mathrm{H}$ atoms by refining the Gram-Charlier coefficients (Johnson \& Levy, 1974) from several X-ray and neutron diffraction measurements.

Aliphatic dicarboxylic $\mathrm{HOOC}\left(\mathrm{CH}_{2}\right)_{n-2} \mathrm{COOH}$ acids with $5 \leq n \leq 13(\mathrm{C} n)$ crystallize in monoclinic space groups (Mortimer et al., 1958; Housty \& Hospital, 1964, 1965a,b, 1966a,b,c, 1967; Sintes et al., 1966; Housty, 1968; Haget et al., 1980; Gao et al., 1994; Bond et al., 2001a,b). The Cn structures show hydrogen-bonded arrangements forming ribbons extended throughout the crystal. Adjacent $\mathrm{C} n$ molecules are connected by hydrogen bonds between the terminal $\mathrm{COOH}$ groups and the interlayer contacts are governed by van der Waals interactions. The dicarboxylic acid structures present
Received 17 February 2003

Accepted 7 April 2003
C 2003 International Union of Crystallography Printed in Great Britain - all rights reserved 
different properties according to the parity of the number of $\mathrm{C}$ atoms in the aliphatic chain. The acids with an even number of $\mathrm{C}$ atoms $(\mathrm{C} p ; p=$ even $)$ crystallize in the space group $P 2_{1} / c$ with two independent molecules per unit cell. In these structures the carboxylic groups of adjacent molecules are related by symmetry (Housty \& Hospital, 1964). The acids with an odd number of $\mathrm{C}$ atoms $(\mathrm{C} q ; q=o d d)$ crystallize in two distinct space groups. The $\alpha$ phase, stable at low temperatures, is described in the space group $P 2_{1} / c$, whereas the $\beta$ phase, stable at high temperatures $(\geq 343 \mathrm{~K})$, is described in space group $C 2 / c$ (Dupré la Tour, 1932). In $\mathrm{C} q$ the interlayer interactions delocalize partially the hydrogen at one end of each dicarboxylic chain resulting in similar $\mathrm{C}=\mathrm{O}$ (double) and $\mathrm{C}-$ O (single) bond distances (Housty, 1968). Thus, in each chain the two $\mathrm{COOH}$ groups are distinguishable and create hydrogen bonds of a different nature.

HMT-C $n$ are 1:1 co-crystals of HMT and $\mathrm{Cn}(5 \leq n \leq 13)$. They all form lamellar structures in which layers of pure HMT stack over layers of pure $\mathrm{C} n$ in the $\mathbf{b}$ direction. Consequently, $b$ is correlated with the distance between the layers of the same chemical composition (pure HMT or pure $\mathrm{C} n$ ). The stabilization of the adducts is essentially ensured by strong $\mathrm{O}-\mathrm{H} \cdots \mathrm{N}$ hydrogen bonds connecting HMT and $\mathrm{C} n$. Weak $\mathrm{C}-\mathrm{H} \cdots \mathrm{O}=\mathrm{C}$ contacts can also be found. Within an HMT layer $\mathrm{C}-\mathrm{H} \cdots \mathrm{N}$ bonds link the HMT molecules. As in pure $\mathrm{C} n$ crystals, the $\mathrm{C} n$ chains are subject to many van der Waals interactions. Interest in investigating this series of compounds is due to their rich structural phase diagrams and the occurrence of modulated structures depending on the chain length and parity of the number $n$ of $\mathrm{C}$ atoms in the dicarboxylic chain.

Bussien Gaillard et al. (1996, 1998) showed that the RT structures of HMT-C $8^{1}$ and HMT-C $10^{2}$ are strongly modulated and can be described in superspace group $P 2_{1} / m(\alpha 0 \beta) 0 s$. The $\mathrm{O}-\mathrm{H} \cdots \mathrm{N}$ hydrogen bonds at opposite ends of the dicarboxylic acid chains are distinguishable. Whereas a well defined $\mathrm{O}-\mathrm{H} \cdots \mathrm{N}$ hydrogen bond was confirmed at one chain end, a delocalization of the $\mathrm{H}$ atom was observed at the other end. HMT-C8 and HMT-C10 exhibit a lock-in phase transition at 123 and $291 \mathrm{~K}$, respectively. The HMT-C10 lock-in phase can be described in the space group $P 2_{1} / c$ as a fourfold superstructure (Gardon et al., 2001). This commensurately modulated phase is characterized by two directions in the layers of C10 chains. In one direction a pair of almost parallel chains, having a common orientation, is followed by another pair differing only by a tilt of the plane chain, thus inducing an $A A B B \ldots$ sequence. The second direction is characterized by the perfect repetition of one type of configurational chain $(A A A A \ldots$ or $B B B B \ldots)$. In HMT-C $9,{ }^{3}$ four different phases have been identified in the thermotropic phase diagram. Phase I $(\geq 343 \mathrm{~K})$ is mainly characterized by the existence of incommensurate phases resulting from a competitive interaction between liquid-crystal and crystalline order (Gardon,

\footnotetext{
${ }^{\mathbf{1}}$ Hexamethylenetetramine suberate.

${ }^{2}$ Hexamethylenetetramine sebacate.

${ }^{3}$ Hexamethylenetetramine azelate.
}

Schenk et al., 2003). Phase II, stable in the temperature range $282 \leq T \leq 350 \mathrm{~K}$, is disordered. Its average structure is described in the non-conventional orthorhombic space group Bmmb (alternate setting of the Cmcm; Bonin et al., 2003). This phase is disordered and characterized by the presence of strong and well organized rods of diffuse scattering in its diffraction pattern. The disorder has been interpreted in terms of a stacking fault model (Bonin et al., 2003). Phase III, stable in the temperature range $236 \leq T \leq 282 \mathrm{~K}$, is described in space group $P 2_{1} / c$. Its structure is characterized by a twinning induced by the II $\Rightarrow$ III phase transition (Hostettler et al., 1999). The low-temperature phase IV of HMT-C9 has the same symmetry as phase III but presents a doubling of one lattice parameter, leading to a structure similar to the lock-in phase of HMT-C10 (Gardon et al., 2001). HMT-C6 crystallizes in space group $\mathrm{Cmcm}$ ( $\mathrm{Li}$ et al., 2001). The crystal structure is ordered and shows a one-dimensional $\mathrm{O}-\mathrm{H} \cdots \mathrm{N}$ hydrogenbonded ribbon. As in crystals of pure $\mathrm{C} 6$ acid, the threedimensional packing of HMT-C6 is characterized by a number of weak van der Waals interlayer contacts.

This work presents a systematic study of the temperature evolution of the structure of HMT-C11, the adduct formed by hexamethylenetetramine and undecanedioic acid. From the melting point down to liquid nitrogen temperature three different structural phases were observed (Fig. 1). Phase I seems to be similar to the high-temperature phase of HMT-C9 (Bonin et al., 2003). Phase II is disordered and its average structure is described in orthorhombic space group Bmmb. Its diffraction pattern is characterized by the presence of strong and regular diffuse scattering rods. This phase is described with the same stacking fault model as used for the corresponding phase of HMT-C9 (Bonin et al., 2003) and HMT-C7 $7^{4}$ (Gardon, Pinheiro \& Chapuis, 2003). Phase III, which is stable between 323 and $93 \mathrm{~K}$ is described in space group $P 2_{1} / c$. This phase is similar to the lock-in phase of HMT-C10 and phase IV of HMT-C9 (Gardon et al., 2001) with the advantage that in HMT-C11 the temperature range stability is larger and that the crystals present macroscopic monodomains.

In the refinements of the HMT-Cn structure performed so far (Bussien Gaillard et al., 1996, 1998; Hostettler et al., 1999; Gardon et al., 2001; Bonin et al., 2003) the $\mathrm{COOH}$ groups are disordered or present large anisotropic displacement parameters (ADPs). Considering the key role played by the $\mathrm{O}$ atoms linking the HMT and $\mathrm{C} n$ molecules, it is particularly interesting to understand the behaviour of the $\mathrm{COOH}$ groups as a function of temperature. With this aim the character of the disorder observed in the $\mathrm{O}$ atoms was analyzed by comparing the refinements performed with split-atom positions and anharmonic displacement parameters. According to Bachmann \& Schulz (1984) a differentiation between these two models can only be inferred from the thermal evolution of the probability density function (PDF) and/or one particle potential (OPP) within a single phase. A detailed evaluation of the $\mathrm{H}$ atoms displacements provided additional information on the constraints imposed on the $\mathrm{COOH}$ group upon cooling.

\footnotetext{
${ }^{\mathbf{4}}$ Hexamethylenetetramine pimelate.
} 
Finally, relevant parameters for the structural phase transitions observed are also pinpointed.

\section{Experimental}

\subsection{Crystal growth and characterization}

In order to synthesize HMT-C11, equimolar amounts of reagent-grade HMT and undecanedioic acid (Fluka) were dissolved in ethanol. The solution was kept at constant temperature and after the complete evaporation of the ethanol, a homogeneous white powder was obtained. Suitable samples for X-ray diffraction studies were grown by slow evaporation of a new solution containing the HMT-C11 raw powder and acetonitrile around room temperature (Bussien Gaillard et al., 1996). Single crystals obtained by this procedure exhibit a preferentially hexagonal tabular habit and are macroscopically twinned. Monodomain samples are obtained by cutting the twinned samples. Differential scanning calorimetry (DSC) analysis of the raw powder as well as finely ground crystals of HMT-C11 revealed two thermotropic phase transitions between the melting point and $120 \mathrm{~K}$ (Fig. 1).

\subsection{Data collection and reduction}

Two samples of HMT-C11 have been investigated by singlecrystal X-ray diffraction. The first sample was used for a data collection performed at $324 \mathrm{~K}$ on an Oxford CCD diffractometer. The CrysAlis software package (Oxford Diffraction, 2001) transformed the CCD frames into integrated intensities. A second sample was used for all the remaining measurements performed at 293, 273, 243, 213, 183, 153, 123 and $93 \mathrm{~K}$ on a Stoe IPDS diffractometer. The Stoe IPDS program suite (Stoe, 1997) was employed to integrate the intensities. The samples were cooled and heated with a nitrogen gas stream controlled by an Oxford Cryostream apparatus (Oxford Cryosystems, 1997). The temperature stability was always better than $1 \mathrm{~K}$. All the measurements were carried out with sealed-tube Mo $K \alpha$ graphite-monochromated radiation. Sample characteristics as well as the relevant data reduction parameters are summarized in Table 1. In order to ensure a direct comparison of the refined quantities, all the data sets below $300 \mathrm{~K}$ have been systematically limited to a resolution of $0.85 \AA$.

\section{Structure solution and refinements}

\subsection{Phases I and II}

The nature of phase $\mathrm{I}(\geq 357 \mathrm{~K})$ is currently unknown. The $\mathrm{X}$-ray diffraction experiments performed so far were inconclusive. This phase seems to have a character intermediate between crystalline and liquid-crystalline, similar to that observed in phase I of HMT-C9 (Gardon, Schenk et al., 2003). Phase II is stable between 357 and $324 \mathrm{~K}$. In this temperature range a superposition of Bragg reflections and diffuse scattering rods are observed in the diffraction pattern. The diffuse rods are parallel to $\mathbf{a}_{\mathrm{II}}^{*}$ and can be indexed by $\xi k l$ indices, where $\xi \in \Re ; k, l \in \mathscr{N}$ (Fig. 1). The diffuse scattering is asso- ciated with a partial disorder of the structure along $\boldsymbol{a}_{\mathbf{I I}}$, whereas the crystal remains perfectly ordered in the other two directions. In order to determine the average structure of phase II only Bragg reflections have been taken into account. The starting structural model was obtained by direct methods using the SHELXS program (Sheldrick \& Schneider, 1997) with space group $B m m b$. Following the disordered model proposed for phase II of HMT-C9 (Bonin et al., 2003) an average structure was built and the position of all $\mathrm{C}, \mathrm{N}$ and $\mathrm{O}$ atoms, as well as their ADPs have been further refined. A total of 106 parameters have been refined according to the function $w R\left(F^{2}\right)$ using the full-matrix least-squares procedure in the SHELXL program (Sheldrick \& Schneider, 1997). H atoms were added according to the riding model (Johnson, 1970a).

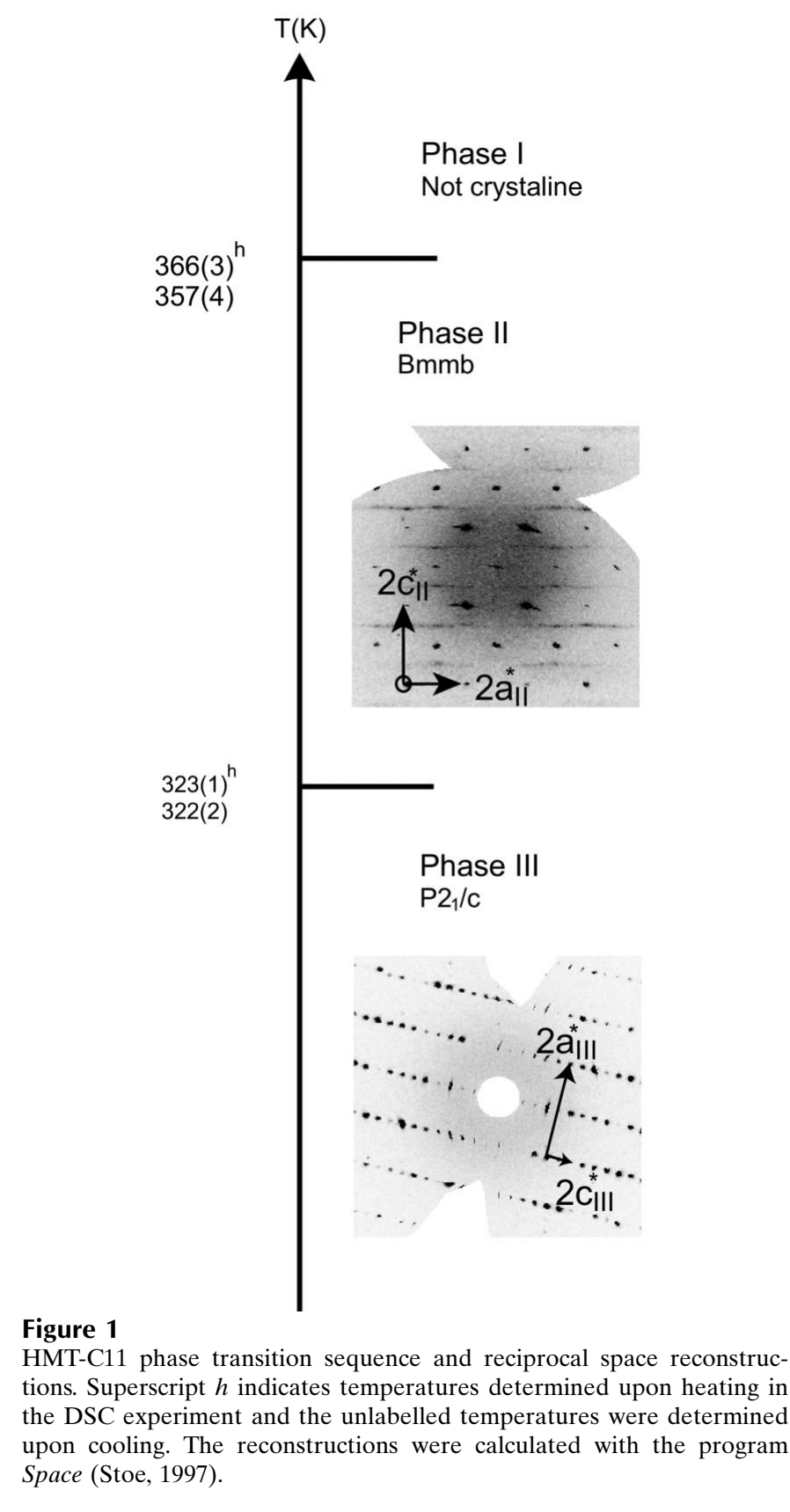


Table 1

Experimental data.

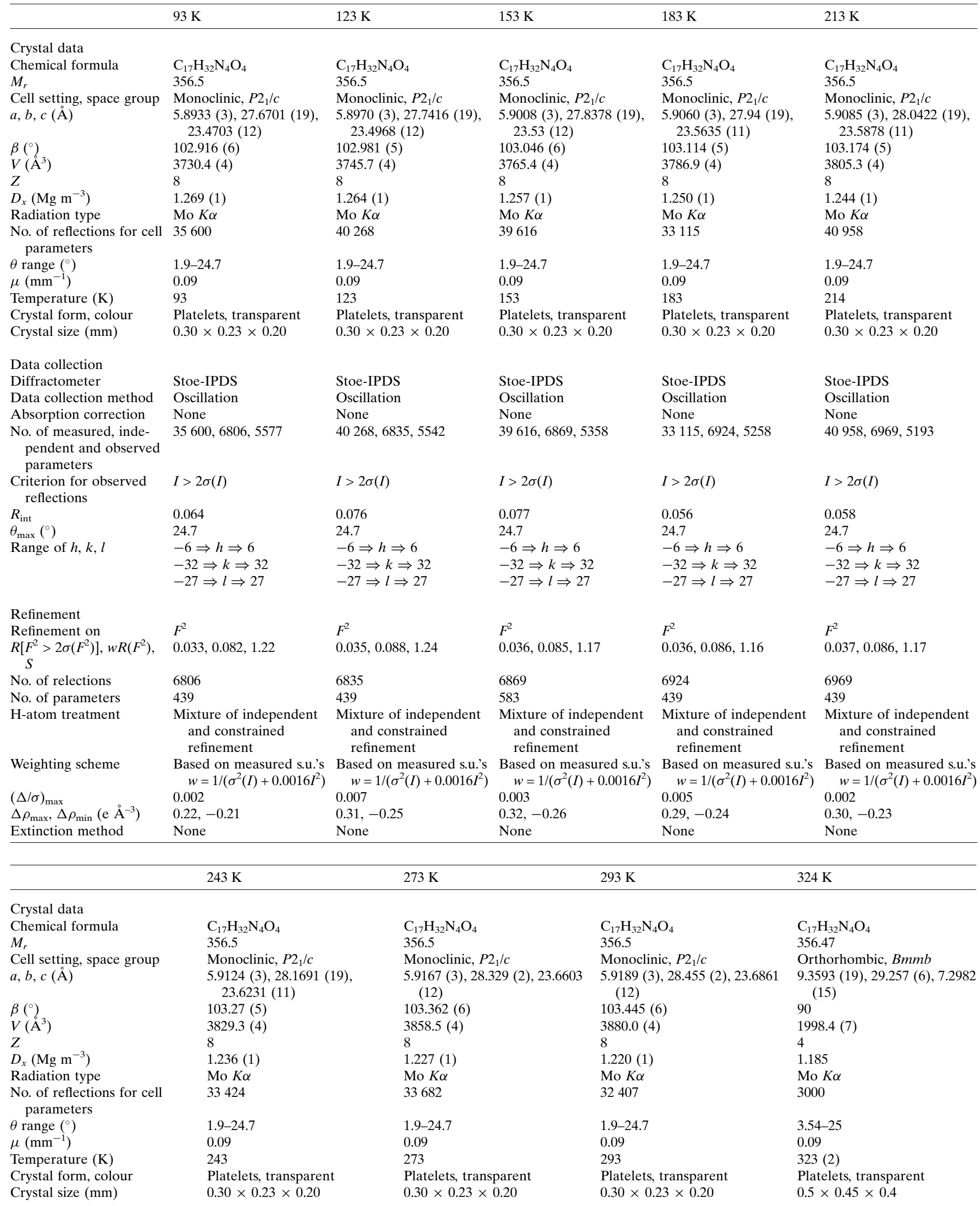


Table 1 (continued)

\begin{tabular}{|c|c|c|c|c|}
\hline & $243 \mathrm{~K}$ & $273 \mathrm{~K}$ & $293 \mathrm{~K}$ & $324 \mathrm{~K}$ \\
\hline \multicolumn{5}{|l|}{ Data collection } \\
\hline Diffractometer & Stoe-IPDS & Stoe-IPDS & Stoe-IPDS & Oxford CCD \\
\hline Data collection method & Oscillation & Oscillation & Oscillation & Oscillation \\
\hline $\begin{array}{l}\text { No. of measured, indepen- } \\
\text { dent and observed para- } \\
\text { meters }\end{array}$ & $33424,6990,4806$ & $33682,7042,4516$ & 32 407, 6266, 4037 & $10013,958,741$ \\
\hline $\begin{array}{l}\text { Criterion for observed reflec- } \\
\text { tions }\end{array}$ & $I>2 \sigma(I)$ & $I>2 \sigma(I)$ & $I>2 \sigma(I)$ & $I>2 \sigma(I)$ \\
\hline$\theta_{\max }\left({ }^{\circ}\right)$ & 24.7 & 24.7 & 24.7 & 25.0 \\
\hline \multirow[t]{3}{*}{ Range of $h, k, l$} & $-6 \Rightarrow h \Rightarrow 6$ & $-6 \Rightarrow h \Rightarrow 6$ & $-6 \Rightarrow h \Rightarrow 6$ & $-10 \Rightarrow h \Rightarrow 11$ \\
\hline & $-33 \Rightarrow k \Rightarrow 33$ & $-33 \Rightarrow k \Rightarrow 33$ & $-33 \Rightarrow k \Rightarrow 33$ & $-34 \Rightarrow k \Rightarrow 34$ \\
\hline & $-27 \Rightarrow l \Rightarrow 27$ & $-27 \Rightarrow l \Rightarrow 27$ & $-27 \Rightarrow l \Rightarrow 27$ & $-8 \Rightarrow l \Rightarrow 8$ \\
\hline \multicolumn{5}{|l|}{ Refinement } \\
\hline Refinement on & $F^{2}$ & $F^{2}$ & $F^{2}$ & $F^{2}$ \\
\hline Weighting scheme & $\begin{array}{l}\text { Based on measured s.u.'s } w= \\
1 /\left(\sigma^{2}(I)+0.0016 I^{2}\right)\end{array}$ & $\begin{array}{l}\text { Based on measured s.u.'s } w= \\
1 /\left(\sigma^{2}(I)+0.0016 I^{2}\right)\end{array}$ & $\begin{array}{l}\text { Based on measured s.u.'s } w= \\
1 /\left(\sigma^{2}(I)+0.0016 I^{2}\right)\end{array}$ & $\begin{array}{l}w=1 /\left[\sigma^{2}\left(F_{o}^{2}\right)+(0.1351 P)^{2}+\right. \\
0.2969 P], \text { where } P=\left(F_{o}^{2}+\right. \\
\left.2 F_{c}^{2}\right) / 3\end{array}$ \\
\hline$(\Delta / \sigma)_{\max }$ & 0.002 & 0.002 & 0.002 & 0.043 \\
\hline$\Delta \rho_{\max }, \Delta \rho_{\min }\left(\mathrm{e} \AA^{-3}\right)$ & $0.24,-0.23$ & $0.24,-0.25$ & $0.22,-0.21$ & $0.14,-0.13$ \\
\hline Extinction method & None & None & None & SHELXL \\
\hline Extinction coefficient & - & - & - & $0.0029(2)$ \\
\hline
\end{tabular}

Computer programs: Stoe-Ipds (Stoe, 1997), SHELXS and SHELXL(Sheldrick \& Schneider, 1997), JANA2000 (Petříček \& Dušek, 2000), KM4 and KMRED (Oxford Diffraction, 2001), XP (Siemens, 1998).

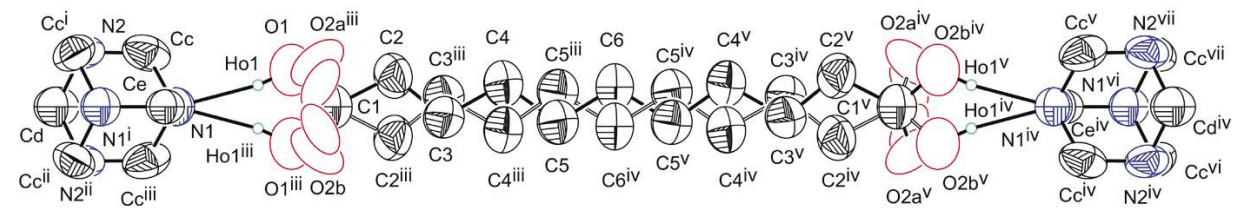

(a)

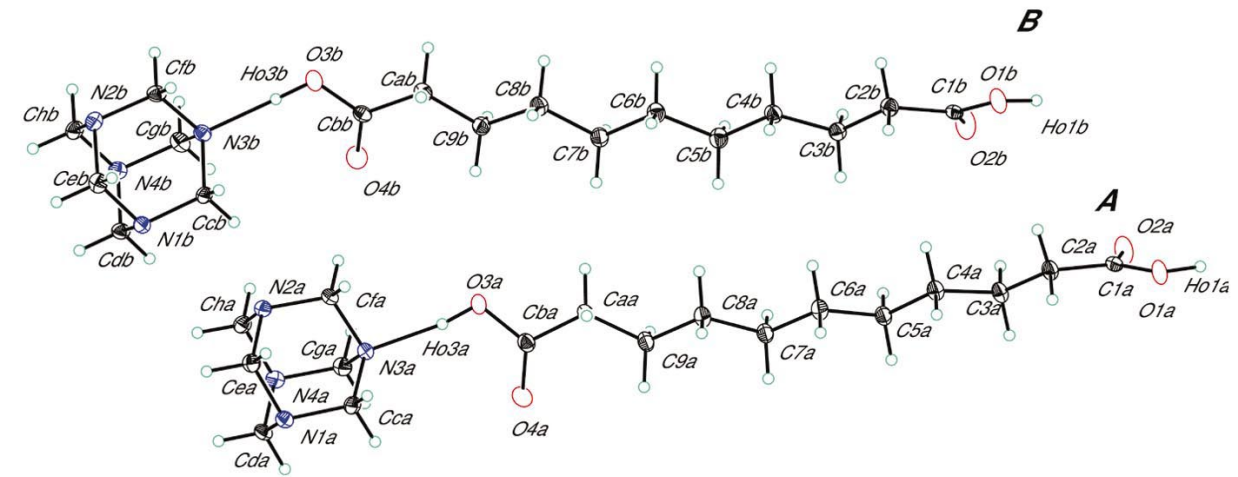

(b)

Figure 2

HMT-C11 molecules in the two investigated phases. All but the $\mathrm{H}$ atoms are represented with $50 \%$ probability ellipsoids. (a) Disordered structure in phase II (324 K). Only the $\mathrm{H}$ atoms linking the HMT and $\mathrm{C} 11$ molecules are shown [(i) $x, \frac{1}{2}-y, z$; (ii) $1-x, \frac{1}{2}-y, z ;$; (iii) $1-x, y, z$; (iv) $1-x, 1-y, 2-z$; (v) $x, 1-y, 2-z$; (vi) $1-x, \frac{1}{2}+y, 2-z$; (vii) $\left.x, \frac{1}{2}+y, 2-z\right]$. (b) Asymmetric structure of phase III ( $93 \mathrm{~K})$. $A$ and $B$ label the two independent molecules. The $\mathrm{O}$ atoms were refined with third anharmonic displacement parameters and are represented in the figure by their approximate harmonic limiting ellipsoids.
The refined structure gives satisfactory results despite the disorder (Table 1). The final difference Fourier maps are flat and do not show peaks

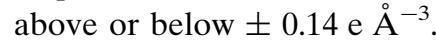

The result of the refinement shows that the HMT molecules are linked to C11 chains with two different orientations (Fig. 2a). Each chain is related to its symmetry equivalent by a mirror plane. Consequently, the occupational factor for each chain is 0.5 . In both orientations the acid chains and the HMT molecules are linked by hydrogen bonds. The precise location of the $\mathrm{H}$ atom linking the HMT and the $\mathrm{C} 11$ molecules was not determined. The $\mathrm{O} 2$ atom (double-bonded to the carbon of the carboxylic group) presents an even more complex disorder as evidenced by its large ADPs. In phase III, as discussed in $\S 3.2$, the double-bonded $\mathrm{O}$ atoms are moving in an anharmonic potential, however, the data quality and chain disorder limited the use of a similar refinement approach in phase II. In 
Table 2

Selected distances $(\AA)$ between atoms in the HMT-C11 asymmetric unit.

OXam and OXbm ( $X=1,2,3$ and 4) represent the maximum of the Probability Density Function for atoms $\mathrm{O} X a$ and $\mathrm{O} X b(X=1,2,3$ and 4) respectively.

\begin{tabular}{lll}
\hline & $293 \mathrm{~K}$ & $93 \mathrm{~K}$ \\
\hline $\mathrm{C} 1 a-\mathrm{C} 2 a$ & $1.491(2)$ & $1.5053(16)$ \\
$\mathrm{C} 2 a-\mathrm{C} 3 a$ & $1.505(3)$ & $1.5180(18)$ \\
$\mathrm{C} 3 a-\mathrm{C} 4 a$ & $1.512(2)$ & $1.5253(16)$ \\
$\mathrm{C} 4 a-\mathrm{C} 5 a$ & $1.508(3)$ & $1.5167(18)$ \\
$\mathrm{C} 5 a-\mathrm{C} 6 a$ & $1.515(2)$ & $1.5231(16)$ \\
$\mathrm{C} 6 a-\mathrm{C} 7 a$ & $1.510(3)$ & $1.5186(18)$ \\
$\mathrm{C} 7 a-\mathrm{C} 8 a$ & $1.521(2)$ & $1.5276(16)$ \\
$\mathrm{C} 8 a-\mathrm{C} 9 a$ & $1.515(3)$ & $1.5210(18)$ \\
$\mathrm{C} 9 a-\mathrm{C} a a$ & $1.513(2)$ & $1.5241(16)$ \\
$\mathrm{C} a a-\mathrm{C} b a$ & $1.489(3)$ & $1.5061(17)$ \\
$\mathrm{C} 1 a-\mathrm{O} 1 a m$ & $1.320(2)$ & $1.3462(12)$ \\
$\mathrm{C} 1 a-\mathrm{O} 2 a m$ & $1.220(2)$ & $1.2268(13)$ \\
$\mathrm{C} b a-\mathrm{O} 3 a m$ & $1.327(2)$ & $1.3375(11)$ \\
$\mathrm{C} b a-\mathrm{O} 4 a m$ & $1.194(2)$ & $1.2132(12)$ \\
& & \\
$\mathrm{C} 1 b-\mathrm{C} 2 b$ & $1.493(2)$ & $1.5076(15)$ \\
$\mathrm{C} 2 b-\mathrm{C} 3 b$ & $1.506(3)$ & $1.5194(18)$ \\
$\mathrm{C} 3 b-\mathrm{C} 4 b$ & $1.513(2)$ & $1.5270(15)$ \\
$\mathrm{C} 4 b-\mathrm{C} 5 b$ & $1.508(3)$ & $1.5223(17)$ \\
$\mathrm{C} 5 b-\mathrm{C} 6 b$ & $1.513(2)$ & $1.5203(18)$ \\
$\mathrm{C} 6 b-\mathrm{C} 7 b$ & $1.511(3)$ & $1.5270(16)$ \\
$\mathrm{C} 7 b-\mathrm{C} 8 b$ & $1.516(2)$ & $1.5210(17)$ \\
$\mathrm{C} 8 b-\mathrm{C} 9 b$ & $1.509(3)$ & $1.5223(16)$ \\
$\mathrm{C} 9 b-\mathrm{C} a b$ & $1.509(2)$ & $1.5049(17)$ \\
$\mathrm{C} a b-\mathrm{C} b b$ & $1.491(3)$ & $1.3450(14)$ \\
$\mathrm{C} 1 b-\mathrm{O} 1 b m$ & $1.330(3)$ & $1.2104(14)$ \\
$\mathrm{C} 1 b-\mathrm{O} 2 b m$ & $1.192(2)$ & $1.3583(11)$ \\
$\mathrm{C} b b-\mathrm{O} 3 b m$ & $1.350(2)$ & $1.2452(14)$ \\
$\mathrm{C} b b-\mathrm{O} 4 b m$ & $1.220(2)$ & \\
\hline & &
\end{tabular}

order to improve the structural model of phase II, the $\mathrm{O} 2$ atom was further split $(\mathrm{O} 2 a$ and $\mathrm{O} 2 b)$. Besides the splitting the resulting geometry of the $\mathrm{COOH}$ group is not chemically reasonable $(\mathrm{C}=\mathrm{O} 2 a \simeq 1.08$ and $\mathrm{C}=\mathrm{O} 2 b \simeq 1.16 \AA)$ and resembles those observed in HMT-C9 (Bonin et al., 2003) and HMT-C7 (Gardon, Pinheiro \& Chapuis, 2003). Better

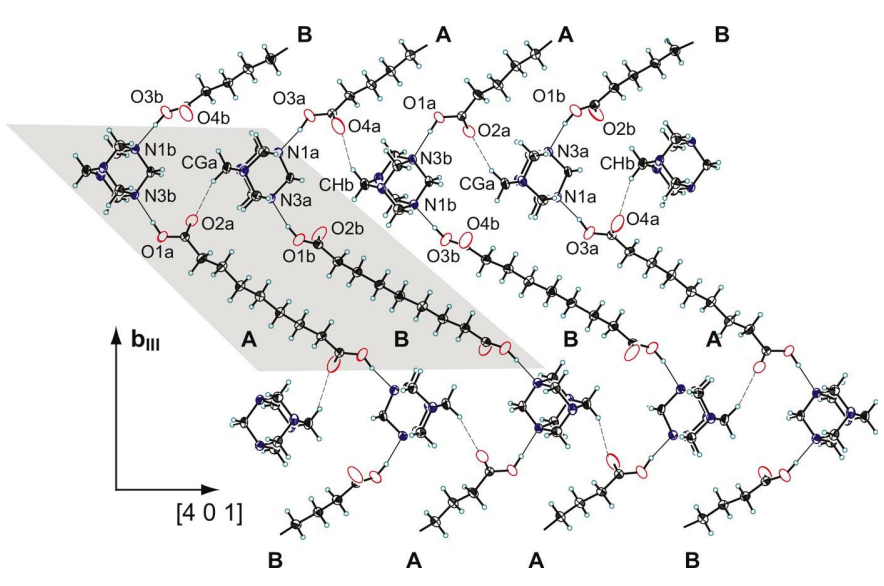

Figure 3

HMT-C11 packing in phase III (93 K). The shadowed area corresponds to the asymmetric unit. Layers of the same chemical composition (only HMT or only $\mathrm{C} n$ ) are packed along $\mathbf{b}_{\text {IIII }}$. Major hydrogen bonding linking the HMT and the $\mathrm{Cn}$ molecules is indicated. The $\mathrm{O}$ atoms are represented by their approximate limiting ellipsoids.
Table 3

Distances $(\AA)$ and angles $\left({ }^{\circ}\right)$ in the $\mathrm{O}-\mathrm{H} \cdots \mathrm{N}$ bonds.

OXam and OXbm ( $X=1,2,3$ and 4) represent the maximum of the Probability Density Function for atoms $\mathrm{O} X a$ and $\mathrm{O} X b(X=1,2,3$ and 4$)$, respectively. At $324 \mathrm{~K}$ the $\mathrm{Ho} 1$ atom is riding the $\mathrm{O} 1$ atom.

\begin{tabular}{|c|c|c|}
\hline $\begin{array}{l}\text { Phase II } \\
\text { N1-O1 } \\
\text { O1-Ho1† } \\
\text { Ho1-N1† } \\
\text { O1-Ho1-N1 }\end{array}$ & & $\begin{array}{l}324 \mathrm{~K} \\
2.7390(6) \\
0.82 \\
1.92 \\
168(1)\end{array}$ \\
\hline Phase III & $293 \mathrm{~K}$ & $93 \mathrm{~K}$ \\
\hline $\begin{array}{l}\mathrm{O} 1 a m-\mathrm{N} 1 b^{\mathrm{i}} \\
\text { O1am-Ho1 } a \\
\text { Ho1 } a-\mathrm{N} 1 b^{\mathrm{i}} \\
\mathrm{O} 1 a m-\mathrm{Ho} 1 a-\mathrm{N} 1 b^{\mathrm{i}}\end{array}$ & $\begin{array}{l}2.7120(9) \\
1.13(2) \\
1.61(2) \\
163(2)\end{array}$ & $\begin{array}{l}2.6958(7) \\
0.99(2) \\
1.72(2) \\
170(2)\end{array}$ \\
\hline $\begin{array}{l}\mathrm{O} 3 a m-\mathrm{N} 3 a \\
\text { Ho } 3 a-\mathrm{O} 3 a m \\
\text { Ho } 3 a-\mathrm{N} 3 a \\
\mathrm{O} 3 a m-\mathrm{Ho} 3 a-\mathrm{N} 3 a\end{array}$ & $\begin{array}{l}2.682(2) \\
1.12(3) \\
1.61(3) \\
159(2)\end{array}$ & $\begin{array}{l}2.616(1) \\
0.83(2) \\
1.80(2) \\
168(2)\end{array}$ \\
\hline $\begin{array}{l}\mathrm{O} 1 b m-\mathrm{N} 1 a^{\mathrm{i}} \\
\text { Ho1b-O } 1 b m \\
\text { Ho } 1 b-\mathrm{N} 1 a^{\mathrm{i}} \\
\mathrm{O} 1 b m-\mathrm{Ho} 1 b-\mathrm{N} 1 a^{\mathrm{i}}\end{array}$ & $\begin{array}{l}2.7364(9) \\
1.17(3) \\
1.61(2) \\
160(2)\end{array}$ & $\begin{array}{l}2.6855(7) \\
0.90(2) \\
1.83(2) \\
160(2)\end{array}$ \\
\hline $\begin{array}{l}\mathrm{O} 3 b m-\mathrm{N} 3 b \\
\text { Ho } 3 b-\mathrm{O} 3 b m \\
\text { Ho } 3 b-\mathrm{N} 3 b \\
\mathrm{O} 3 b m-\mathrm{Ho} 3 b-\mathrm{N} 3 b\end{array}$ & $\begin{array}{l}2.696(2) \\
1.04(3) \\
1.67(3) \\
166(2)\end{array}$ & $\begin{array}{l}2.650(1) \\
0.89(2) \\
1.77(2) \\
167(2)\end{array}$ \\
\hline
\end{tabular}

Symmetry code: (i) $2-x,-\frac{1}{2}+y, \frac{3}{2}-z . \quad \dagger$ Values not refined.

distances would probably be found by refining anharmonic and libration displacement parameters for the $\mathrm{COOH}$ group.

\subsection{Phase III}

The structure from the data collected at RT, 273, 243, 213, $183,153 \mathrm{~K}, 123$ and $93 \mathrm{~K}$ have been obtained in space group $P 2_{1} / c$ by direct methods using the SHELXS97 program (Sheldrick \& Schneider, 1997). The positions of all C, N and O atoms could always be unambiguously assigned to the two independent HMT-C11 molecules. All the $\mathrm{H}$ atoms have been localized on consecutive difference-Fourier maps. Initial attempts to refine the RT structure using SHELXL97 (Sheldrick \& Schneider, 1997) indicated unacceptably large ADPs for the $\mathrm{O}$ atoms of the carboxyl groups. Similar refinements of the lower-temperature measurements (273, 243 and $213 \mathrm{~K}$ ) confirmed this unusual feature. Two possible structural models were further investigated. In the first model the $\mathrm{O}$ atoms of the $\mathrm{COOH}$ groups were considered as statistically disordered and refined with split positions subject to constrained $\mathrm{C}=\mathrm{O}$ bond distances. In the second model the $\mathrm{O}$ atoms of the $\mathrm{COOH}$ groups were refined subject to third-order anharmonic displacement parameters (Kuhs, 1992). This second analysis was performed using the package JANA2000 (Petrríček \& Dušek, 2000). In both models the $H$ atoms linking the HMT and the C11 molecules were freely refined and all the others were supposed to ride on the nearby C atom (Johnson, 1970a).

3.2.1. Split-atom model. In this model the four independent double-bonded $\mathrm{O}$ atoms of the carboxylic groups are split. The 
oxygen ADPs were refined independently, but the sum of the occupation parameters for each couple of split atoms was constrained to one. The ratio between the number of refined parameters and the number of reflections was at least 12 (data refinement at $293 \mathrm{~K}$ ). A total of 507 parameters have been refined minimizing the function $w R\left(F^{2}\right)$ using the full-matrix least-squares procedure for all investigated temperatures.

The distance between the split $\mathrm{O}$ atoms decreased upon cooling. At $123 \mathrm{~K}$ the atom labelled $\mathrm{O} 2 b$ could no longer be split. For one of the two split atoms some $U^{i j}$ became nonpositive definite and its occupational parameter moved to a value close to zero. At $93 \mathrm{~K}$, three out of four $\mathrm{O}$ atoms could not be split. Only the disordered $\mathrm{O}$ atom labelled $\mathrm{O} 4 a$ could still be resolved: the distance between its two split positions was 0.19 (3) $\AA$. This result indicates that the disordered model based on split $\mathrm{O}$ atoms is not describing an intrinsic property of phase III but rather modelling the uncommon electronic distribution around the $\mathrm{O}$ atoms at high temperatures. Upon cooling it is no longer necessary to use multiple atomic positions to describe the unusual feature in the electron density. For a system with a genuine static disorder, the opposite behaviour would be expected. Following the reduction of the ADPs, the two split positions should be unambiguously resolved and not merge together at a certain temperature. From the above statements and from the analysis of the anharmonic model described in the next section, the description of phase III of HMT-C11 based on the split-atom model was considered somehow artificial and will not be further discussed here.

3.2.2. Anharmonic model. The anharmonic refinement starting model is based on the structure solution obtained by direct methods without split $\mathrm{O}$ atoms. In order to maximize the observation-to-parameter ratio, some simplifications have been introduced. For instance, analysis of the ADPs of the N

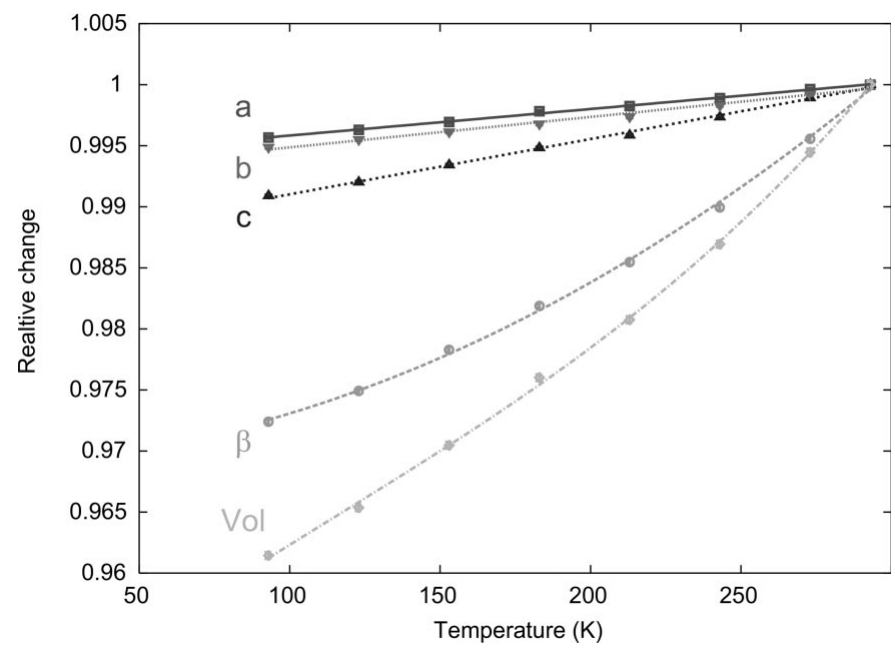

Figure 4

Relative change of the lattice parameters of HMT-C11 in phase II upon cooling. Lattice parameters at $293 \mathrm{~K}$ were used as a reference. The $a, c$ and $\beta$ curves were fitted with first-order polynomials, while the $b$ and volume curves were adjusted with second-order polynomials. $b$ is the lattice parameter correlated with the distance between the layers of the same chemical nature as indicated in Fig. 3.
Table 4

Distance between $\mathrm{O} 4 a$ and $\mathrm{O} 4 b$ atoms and their neighbours in phase III ( $)$.

O4am and O4bm represent the maximum of the Probability Density Function for atoms $\mathrm{O} 4 a$ and $\mathrm{O} 4 b$, respectively.

\begin{tabular}{|c|c|c|}
\hline & $293 \mathrm{~K}$ & $93 \mathrm{~K}$ \\
\hline $\mathrm{O} 4 a m-\mathrm{O} 3 a$ & 2.236 & 2.2478 \\
\hline $\mathrm{O} 4 a m-\mathrm{C} a \mathrm{a}$ & $2.3578(19)$ & 2.3859 (13) \\
\hline $\mathrm{O} 4 a m-\mathrm{C} 9 a$ & 2.8712 (17) & 2.9015 (12) \\
\hline $\mathrm{O} 4 a m-\mathrm{H} 3 a$ & $2.29(2)$ & $2.333(15)$ \\
\hline $\mathrm{O} 4 a m-\mathrm{H} h a b^{\mathrm{i}}$ & $2.5978(10)$ & $2.496(9)$ \\
\hline $\mathrm{O} 4 a m-\mathrm{H} e b b^{\mathrm{ii}}$ & 2.5377 (11) & $2.498(9)$ \\
\hline $\mathrm{O} 4 a m-\mathrm{H} 9 a a$ & 2.6147 & $2.622(10)$ \\
\hline $\mathrm{O} 4 a m-\mathrm{H} a a b^{\mathrm{iii}}$ & 3.6098 & $3.633(12)$ \\
\hline $\mathrm{O} 4 a m-\mathrm{H} a \mathrm{ab}$ & 2.799 & $2.811(12)$ \\
\hline $\mathrm{O} 4 a m-\mathrm{H} d b b^{\mathrm{i}}$ & $2.9337(9)$ & $2.790(8)$ \\
\hline $\mathrm{O} 4 a m-\mathrm{Heab}{ }^{\mathrm{ii}}$ & $3.2546(11)$ & $3.383(9)$ \\
\hline $\mathrm{O} 4 a m-\mathrm{H} e a b^{\mathrm{i}}$ & $3.2165(10)$ & $2.958(9)$ \\
\hline $\mathrm{O} 4 b m-\mathrm{O} 3 b$ & 2.2468 & 2.2772 \\
\hline $\mathrm{O} 4 b m-\mathrm{C} a b$ & 2.4147 (19) & $2.4377(13)$ \\
\hline $\mathrm{O} 4 b m-\mathrm{C} 9 b$ & $2.8926(17)$ & $2.8976(12)$ \\
\hline $\mathrm{O} 4 b m-\mathrm{C} f a$ & $3.1940(19)$ & 3.1579 (14) \\
\hline $\mathrm{O} 4 b m-\mathrm{H} 3 b$ & $2.31(2)$ & 2.349 (15) \\
\hline $\mathrm{O} 4 b m-\mathrm{H} f b a$ & $2.6934(11)$ & $2.706(9)$ \\
\hline $\mathrm{O} 4 b m-\mathrm{H} 9 b a$ & 2.7303 & $2.744(10)$ \\
\hline $\mathrm{O} 4 b m-\mathrm{H} h b a^{\mathrm{iv}}$ & $2.8683(10)$ & $2.778(8)$ \\
\hline $\mathrm{O} 4 b m-\mathrm{H} f a a$ & $2.8252(10)$ & $2.786(8)$ \\
\hline $\mathrm{O} 4 b m-\mathrm{H} 8 b b^{\mathrm{iii}}$ & 2.9602 & $2.787(12)$ \\
\hline $\mathrm{O} 4 b m-\mathrm{H} 9 b b$ & 2.9463 & $2.950(11)$ \\
\hline $\mathrm{O} 4 b m-\mathrm{H} a b b$ & 3.1332 & 3.077 (12) \\
\hline $\mathrm{O} 4 b m-\mathrm{H} a b b^{\mathrm{iii}}$ & 2.9733 & $2.996(12)$ \\
\hline $\mathrm{O} 4 b m-\mathrm{H} a b a$ & 3.0401 & $3.066(12)$ \\
\hline $\mathrm{O} 4 b m-\mathrm{H} c a b$ & $3.2139(10)$ & $3.101(8)$ \\
\hline $\mathrm{O} 4 b m-\mathrm{H} g b b$ & $3.3753(9)$ & $3.325(8)$ \\
\hline $\mathrm{O} 4 b m-\mathrm{N} 3 b$ & $3.4488(15)$ & 3.4383 (11) \\
\hline $\mathrm{O} 4 b m-\mathrm{H} 6 b a^{\mathrm{v}}$ & 3.5902 & 3.455 (11) \\
\hline
\end{tabular}

Symmetry codes: (i) $1+x, \frac{3}{2}-y, \frac{1}{2}+z$; (ii) $x, \frac{3}{2}-y, \frac{1}{2}+z$; (iii) $-1+x, y, z$; (iv) $1+x, y, z ;(\mathrm{v}) 1-x, 1-y, 1-z$.

and $\mathrm{C}$ atoms of the HMT molecule strongly suggests a rigidbody motion, as reported in previous works (Terpstra et al., 1993; Kampermann et al., 1995; Bürgi et al., 2000). Thus, the two independent HMT molecules have not been refined individually. Instead, a rigid HMT molecule has been refined for each independent position. In addition, the individual ADPs were replaced by a TLS tensor (Johnson, 1970b). The atomic coordinates of the HMT rigid molecule as well as its translation and rotation parameters were adjusted during the least-squares refinement. To summarize, in all the refinements performed with JANA2000, the following strategy was adopted:

(i) refinement of the initial model;

(ii) refinement considering the HMT molecules as rigid bodies with individual ADPs replaced by TLS;

(iii) inclusion of riding $\mathrm{H}$ atoms;

(iv) refinement of the third-order anharmonic displacement parameters for the $\mathrm{O}$ atoms of the carboxylic molecule.

In total, 439 parameters have been refined minimizing the function $w R\left(F^{2}\right)$ using a full-matrix least-squares procedure. The final residual map does not show peaks above/below $\pm 0.21 \mathrm{e}^{-3}$ at $293 \mathrm{~K}$ and \pm 0.29 e $\AA^{-3}$ at $93 \mathrm{~K}$. Despite the reduction of 68 parameters, the final $R$ values obtained for the anharmonic model are notably smaller than those obtained 
with the split-atom model (data not shown). Fig. 2(b) shows the asymmetric unit in this phase.

In phase III the HMT molecules form layers normal to $\mathbf{b}_{\text {III }}$, while the two distinct $\mathrm{C} 11$ chains $(A$ and $B)$ are aligned in the plane $(10 \overline{4})$, as indicated in Fig. 3. The planes of the $\mathrm{COOH}$ terminal groups have a different orientation at each end of the C11 chains. In $A$ they are rotated by +45 and $-39^{\circ}$ relative to the best plane defining the chain (relative rotation of $84^{\circ}$ ), while in $B$ they are rotated by +28 and $+11^{\circ}$ (relative rotation of $17^{\circ}$ ). These values refer to the RT structure refinement. The $\mathrm{C}-\mathrm{O}$ and $\mathrm{C}=\mathrm{O}$ bonds are always well defined. The $\mathrm{O} 1 a, b$

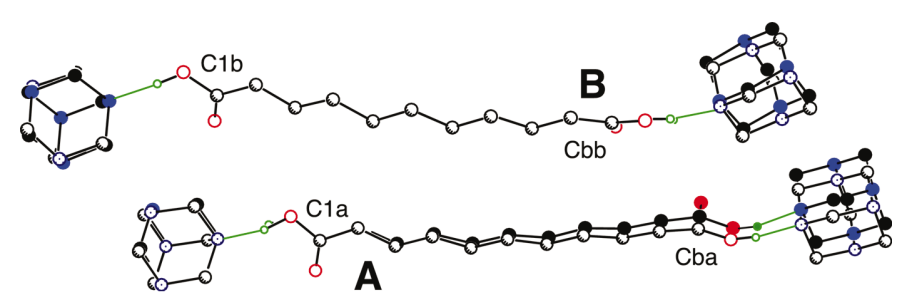

(a)

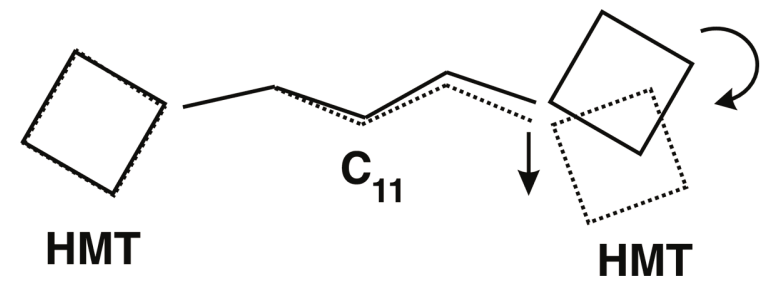

(b)

Figure 5

(a) Superposition of the HMT-C11 asymmetric unit refined at $293 \mathrm{~K}$ (open circles) and $93 \mathrm{~K}$ (full circles). The chain superposition was calculated with Cerius2 (Molecular Simulations Inc., 1997) using only the $\mathrm{C}$ atoms of chain $B$. Upon cooling the major structural changes observed are a shearing of consecutive HMT (or C11) planes and the rotation of the HMT molecules. The strong $\mathrm{O}-\mathrm{H} \cdots \mathrm{N}$ bond $(\mathrm{O}-\mathrm{N}$ distance and $\mathrm{O}-\mathrm{H} \cdots \mathrm{N}$ angle) is preserved. (b) Schematic view of the relative movements.

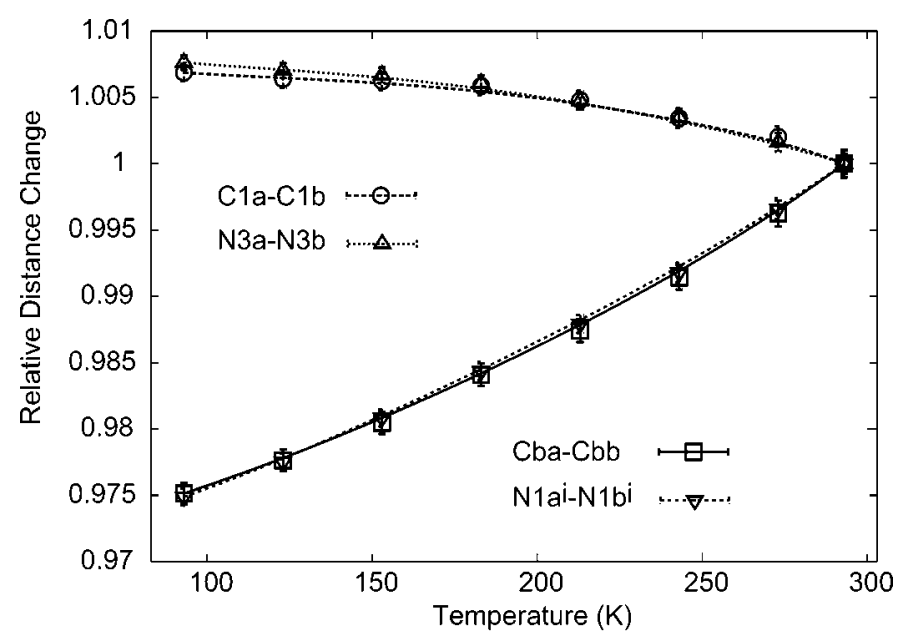

Figure 6

Relative distance between the end $\mathrm{C}$ atoms in the $A$ and $B$ chains of the $\mathrm{C} 11$ molecules $(\mathrm{C} 1 a-\mathrm{C} 1 b$ and $\mathrm{C} b a-\mathrm{C} b b)$ and between the $\mathrm{N} 1 a^{\mathrm{i}}-\mathrm{N} 1 b^{\mathrm{i}}$ and $\mathrm{N} 3 a-\mathrm{N} 3 b$ atoms from the HMT molecule [(i) $2-x,-\frac{1}{2}+y, \frac{3}{2}-z$ ]. $\mathrm{C} 1 a-\mathrm{N} 1 a^{\mathrm{i}}, \mathrm{C} 1 b-\mathrm{N} 1 b^{\mathrm{i}}, \mathrm{C} b a-\mathrm{N} 3 a$ and $\mathrm{C} b b-\mathrm{N} 3 b$ are related through $\mathrm{C}-\mathrm{O}-\mathrm{H} \cdots \mathrm{N}$ bonds. and the $\mathrm{O} 3 a, b$ atoms form the $\mathrm{O}-\mathrm{H} \cdots \mathrm{N}$ hydrogen bonds linking the HMT and $\mathrm{C} 11$ molecules. The $\mathrm{O} 2 a, b$ and $\mathrm{O} 4 a, b$ atoms (double-bonded) exhibit a unique neighbourhood: both the number and position of the nearby atoms are different. Their pronounced anharmonic displacement parameters express a high degree of freedom and might be correlated with the change in the nature or number of intermolecular contacts (weak $\mathrm{C}-\mathrm{H} \cdots \mathrm{O}=\mathrm{C}$ bonds) upon cooling.

No remarkable structural change was observed in the refinements performed within phase III as a function of the temperature. Selected distances between atoms are listed in Tables 2-4. The distances between $\mathrm{O}$ and the other atoms do not refer to the oxygen mean positions, but rather to the maximum of the oxygen PDFs, herein named OXam and $\mathrm{OXbm}(X=1,2,3$ and 4$)$. This is a necessary correction since in the high-order refinements the mean and the standard deviation of the harmonic part include the anharmonic shifts (Kuhs, 1992). Corrections due to the coupled motions were not taken into account here. The structural parameters for all other investigated temperatures have been deposited. ${ }^{\mathbf{5}}$

\section{Discussion}

\subsection{Lattice parameters}

The lattice parameters of phase II and phase III are related as follows: $2 \mathbf{a}_{\text {III }}=\mathbf{a}_{\text {II }}+\mathbf{c}_{\text {III }} ; \mathbf{b}_{\text {III }}=\mathbf{b}_{\text {II }}$ and $\mathbf{c}_{\text {III }}=\left(\mathbf{c}_{\text {II }}-\mathbf{a}_{\text {III }}\right)$. Within phase III the lattice parameters of the HMT-C11 change continuously, as indicated in Fig. 4 . All but the $b$ parameter change almost linearly with temperature. The RMS for the residuals of the $a(T) / a(293 \mathrm{~K}), c(T) / c(293 \mathrm{~K})$ and $\beta(T) /$ $\beta(293 \mathrm{~K})$ fittings are smaller than $2 \times 10^{-4}$. The evolution of the $b(T) / b(293 \mathrm{~K})$ ratio with temperature is described by a second-order polynomial (RMS $=4 \times 10^{-4}$ ) and accordingly the volume ratio was also fitted with a similar curve (RMS = $\left.1.4 \times 10^{-3}\right) . b$ is the direction normal to the HMT and C11 layers. Since $b$ is the most sensitive parameter it might be concluded that the layer separation is the dominant feature in the HMT-C11 structural packing below the II $\Rightarrow$ III phase transition. In other words the HMT layers can be seen as compact two-dimensional structures contributing to the global three-dimensional packing by simply forcing an angular change of the $\mathrm{C} 11$ chains and consequently the contraction (or expansion) of the $b$ lattice parameter.

\subsection{Acidity of the $\mathrm{C} 11$ chain}

In the incommensurate structures of HMT-C 8 and HMTC10 deprotonation on one end of the $\mathrm{C} n(n=8,10)$ acid chains was observed (Bussien Gaillard et al., 1996, 1998). The analysis of the four-dimensional electron density maps led the previous authors to conclude that one hydrogen bridge atom should be partially delocalized within a triangle formed by the two carboxylic oxygen atoms and a nitrogen atom of the HMT molecule. The nature of this particular chemical bond was not

\footnotetext{
${ }^{5}$ Supplementary data for this paper are available from the IUCr electronic archives (Reference: NA0146). Services for accessing these data are described at the back of the journal.
} 
determined. Hostettler et al. (1999) pointed out that in phase III of HMT-C9, the C9 chains exclusively adopt two forms, pure carboxylic or pure carboxylate, and that the carboxylic is the most abundant. These conclusions were based on measurements performed on a twinned sample with structural refinement based on a split-atom model. In the lock-in phase of HMT-C10, all the $\mathrm{COOH}$ groups display a clear acid character (carboxylic) despite the rather long $\mathrm{O}-\mathrm{H}$ distance (Gardon et al., 2001).

In the structure refinements of phase II $(324 \mathrm{~K})$, the positions of the $\mathrm{H}$ atoms linking the HMT and the $\mathrm{C} 11$ molecules were not determined. However, in the investigation of phase III, these $\mathrm{H}$ atoms were always found close to the single-

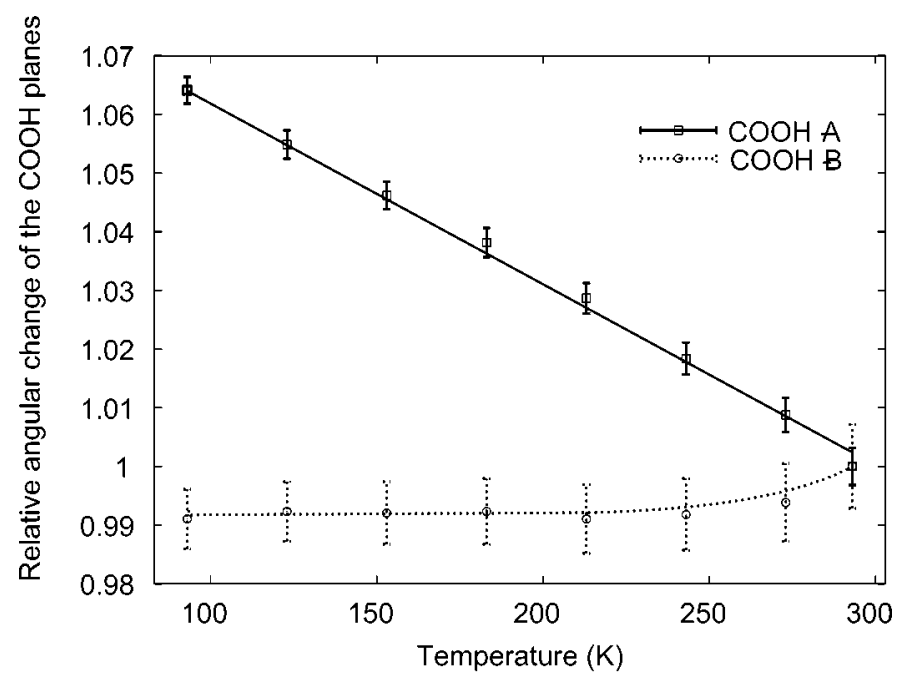

Figure 7

Relative rotation of the terminal carboxylic groups upon cooling. The $\mathrm{COOH}$ groups of chain $A$ rotate linearly relative to each other, while the $\mathrm{COOH}$ groups of chain $B$ hardly rotate at all upon cooling.

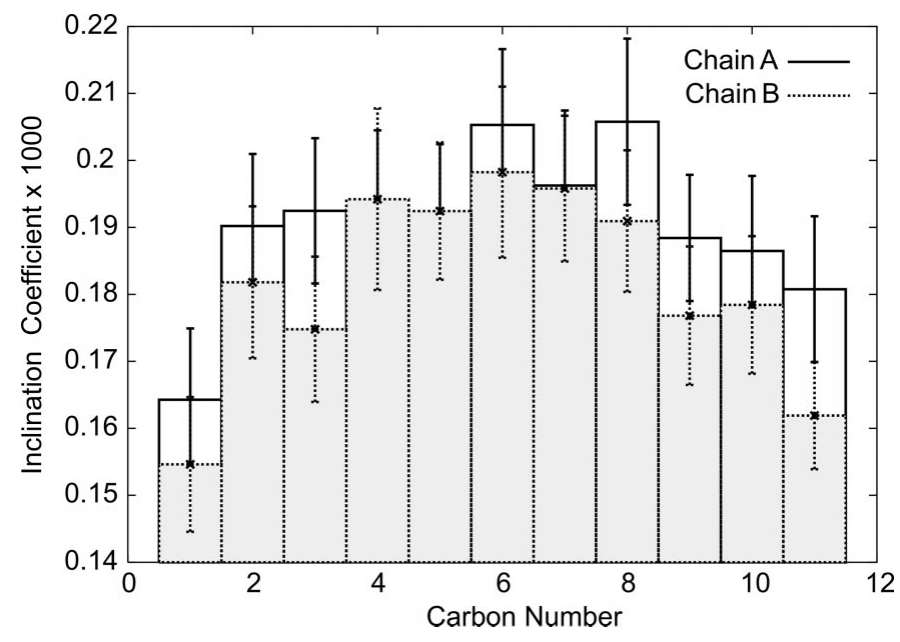

Figure 8

The displacement parameters of the $\mathrm{C}$ atoms in the chains change almost linearly upon cooling and were approximated by the $U_{\text {eq }}(T)=u_{l} T+v_{l}$ function ( $l$ runs for the $\mathrm{C}_{l}$ atoms). Consequently, high $u_{l}$ values indicate the $\mathrm{C}$ atoms whose $U_{\text {eq }}$ values change more upon cooling. The figure indicate the $u_{l}$ values for each $\mathrm{C}$ atom $l$ within $A$ (white bars) and $B$ (grey bars) chains. bonded $\mathrm{O}$ atom of the carboxylic group (O1a,b and $\mathrm{O} 3 a, b)$. All attempts to split the $\mathrm{H}$ atoms between the acid chain and the HMT molecule failed. Nevertheless, the $\mathrm{O}-\mathrm{H}$ distances decrease systematically during the cooling (data not shown), enhancing clearly the acid character of the $\mathrm{C} 11$ chain. The average $\mathrm{O}-\mathrm{H} \cdots \mathrm{N}$ distance is $2.71(2) \AA$ at $293 \mathrm{~K}$ and $2.66(4) \AA$ at $93 \mathrm{~K}$. The $\mathrm{O}-\mathrm{H} \cdots \mathrm{N}$ distance value does not change systematically during the cooling and the difference in the values might be due to the neglecting of the correlated displacements. Table 3 shows the $\mathrm{O}-\mathrm{H} \cdots \mathrm{N}, \mathrm{O}-\mathrm{H}$ and $\mathrm{H} \cdots \mathrm{N}$ distances as well as the $\mathrm{O}-\mathrm{H} \cdots \mathrm{N}$ angles in the four independent $\mathrm{COOH}$ groups at 293 and $93 \mathrm{~K}$. Notably Hol $a$ and $\mathrm{Ho} 3 a$ form the most flexible $\mathrm{O}-\mathrm{H} \cdots \mathrm{N}$ bonds.

\subsection{Relative $\mathrm{C} 11$ chain motion}

In phase III the distances and angles between the $\mathrm{C}$ atoms within $A$ and $B$ chains are rather constant (Table 2). The overall change in the $\mathrm{C}$-atom positions in each single chain was estimated by superimposing the structures refined at different temperatures. The RMS values for the superposition of structures refined at $T_{i}$ and $T_{i}-30 \mathrm{~K}$ are smaller than $0.008 \AA$ and smaller than $0.04 \AA$ for the superposition of the structures refined at 293 and $93 \mathrm{~K}$. These results indicate that the $\mathrm{C} 11$ molecules behave like rigid bodies within the studied temperature interval.

Fig. 5(a) shows the superposition of the asymmetric unit of HMT-C11 at 293 and $93 \mathrm{~K}$, in which chain $B$ was taken as a reference. The most remarkable displacements are schematically represented in Fig. 5(b): the angular changes of chain $A$ and the rotation of its neighbouring HMT molecule. All HMTC11 displacements are subject to the constraints imposed by the strong $\mathrm{O}-\mathrm{H} \cdots \mathrm{N}$ bond between HMT and $\mathrm{C} 11$ molecules and by packing interactions which force the HMT to rotate around an axis almost perpendicular to the plane of the chains

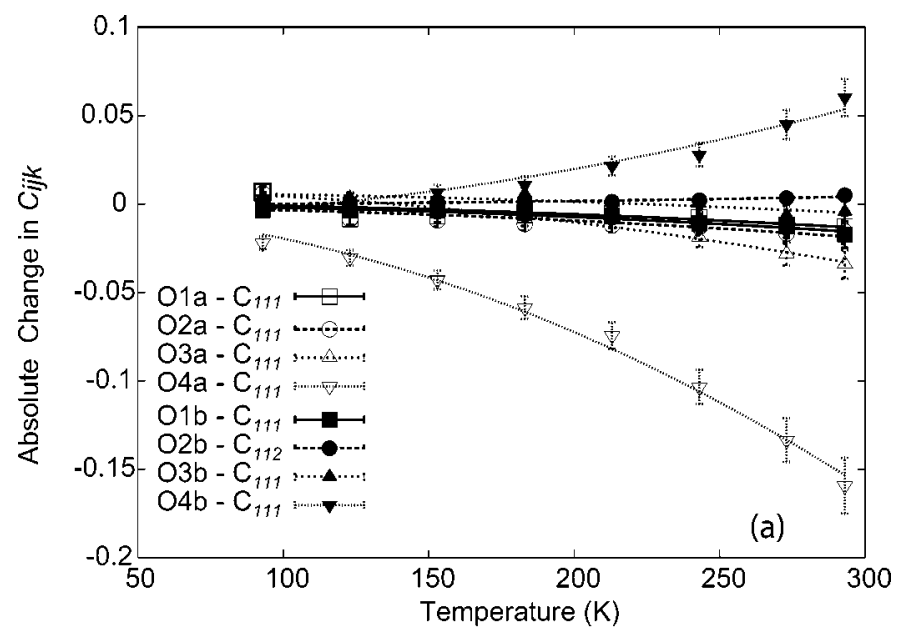

Figure 9

Absolute change of the most relevant $C_{i j k}$ coefficients as a function of temperature for each $\mathrm{O}$ atom in the carboxylic group. Each coefficient was fit according to $C_{i j k}(T)=K_{1} T+K_{2} T^{2}$, where $K_{1}$ and $K_{2}$ are arbitrary coefficients. 
tilt. Fig. 2(b) shows that the $\mathrm{C} 11$ chains in the asymmetric unit have a helical distortion. Thus, no plane defining each chain individually can be determined with accuracy. The quantitative relative movement of the chains was determined by calculating the distance between pairs of similar $\mathrm{C}$ atoms from different chains $(\mathrm{Ci}-\mathrm{Cib})$ at each refined temperature. The largest distance changes occur between the terminal $\mathrm{Cba}-$ $\mathrm{C} b b$ atoms. Fig. 6 shows the behaviour of the distance change of $\mathrm{C}$ atoms $\mathrm{C} b a-\mathrm{C} b b$ and $\mathrm{C} 1 a-\mathrm{C} 1 b$ located on the opposite side of the $\mathrm{C} 11$ chains. Note that while $\mathrm{C} b a-\mathrm{C} b b$ atoms become closer, $\mathrm{C} 1 a$ and $\mathrm{C} 1 b$ move slightly away from each other, indicating that the relative HMT movement on each end of the C11 chain is opposite. Fig. 6 also shows the perfect correlation between the relative displacement of the last C11 chain's $\mathrm{C}$ atoms and the $\mathrm{N}$ atoms of the HMT participating in the hydrogen bonds $\mathrm{N} 1 a^{\mathrm{i}}-\mathrm{N} 1 b^{\mathrm{i}}$ and $\mathrm{N} 3 a-\mathrm{N} 3 b \quad$ [(i) $\left.2-x,-\frac{1}{2}+y, \frac{3}{2}-z\right]$.

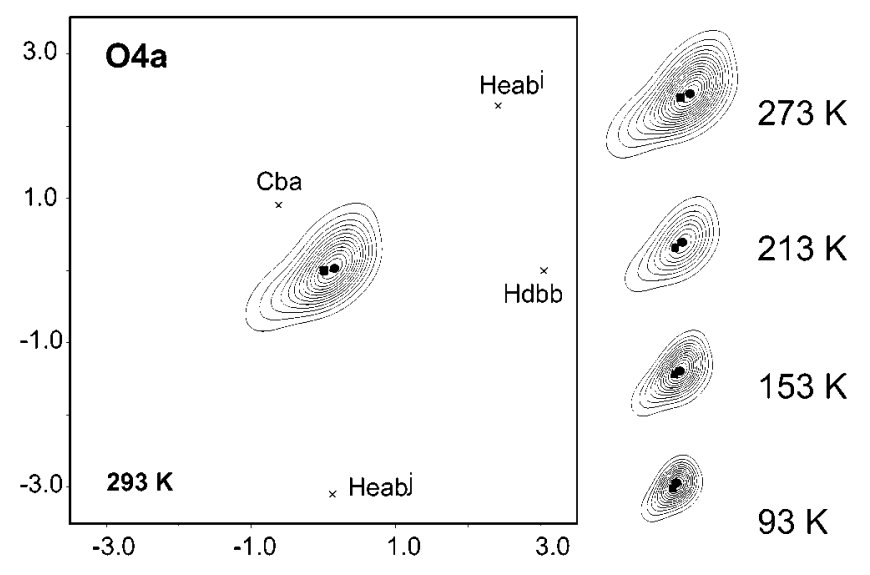

(a)

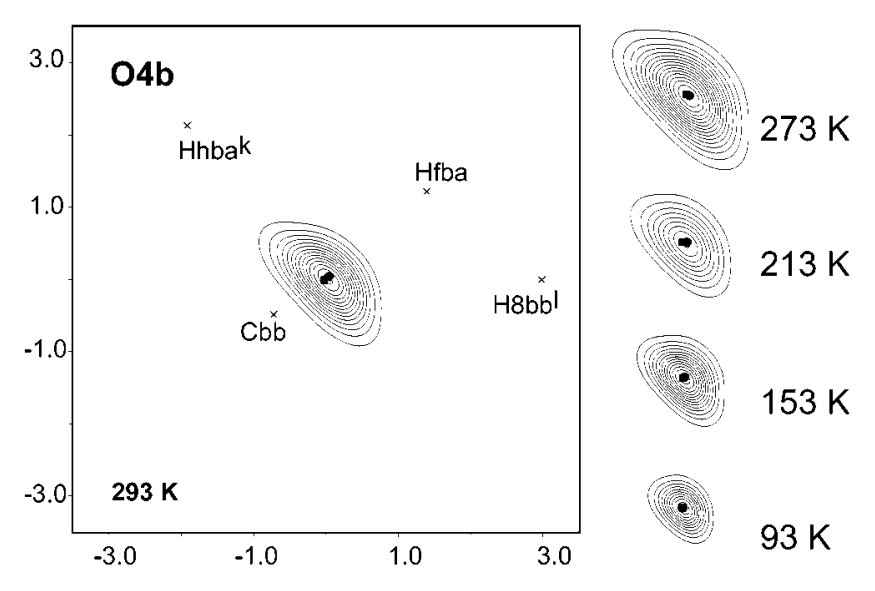

(b)

\section{Figure 10}

Probability density function ( $a$ ) for atoms $\mathrm{O} 4 a$ in the $\mathrm{H} d b b-\mathrm{O} 4 a m-$ $\mathrm{H} e a b^{\mathrm{i}}$ plane and $(b)$ for atoms $\mathrm{O} 4 b$ in the $\mathrm{H} 8 b b^{\mathrm{iv}}-\mathrm{O} 4 b m-\mathrm{H} h b a^{\mathrm{iii}}$ plane at different temperatures. In both figures the additional $\mathrm{H}$ atom positions are projected over the mentioned planes. The square indicates the atomic average position and the circle the maximum of the PDF function [(i) $1+x, \frac{3}{2}-y, \frac{1}{2}+z$; (ii) $x, \frac{3}{2}-y, \frac{1}{2}+z$; (iii) $1+x, y, z$; (iv) $\left.-1+x, y, z\right]$.

\subsection{Rotation of the carboxylic group}

The superposition of the $\mathrm{C} 11$ chains discussed above reveals that the $\mathrm{COOH}$ planes also rotate upon cooling. The rotation was estimated by calculating the dihedral angles between the best planes defining the two terminal $\mathrm{COOH}$ groups of each chain type as a function of temperature (Fig. 7). Upon cooling the two carboxylic groups attached to chain $A$ rotate with a linear temperature dependence relative to each other. The carboxylic groups at each end of chain $B$ rotate in the opposite direction between 293 and $273 \mathrm{~K}$. Their rotation almost stops below $243 \mathrm{~K}$.

In the refined model of phase II the $\mathrm{COOH}$ groups present a more complex configuration than the simple superposition of the two orientations observed for the $\mathrm{C}$ atoms in the chains. This is evident from the disorder (split) and large oxygen ADPs observed in this phase (Fig. $2 a$ ). In phase III the $\mathrm{COOH}$ groups adopt rather distinct orientations on each side of the two independent chains of the asymmetric unit and, in addition, a continuous relative change of the $\mathrm{COOH}$ orientation was detected in one chain upon cooling. Owing to these observations one can postulate that a coupling of the chain movement along $\mathbf{b}_{\mathbf{I I}}$ (or $\mathbf{b}_{\text {III }}$ ) and the $\mathrm{COOH}$ group rotation might take place during the structure evolution, including the II $\Rightarrow$ III phase transition, preserving the strong $\mathrm{O}-\mathrm{H} \cdots \mathrm{N}$ bond linking C11 to HMT.

\subsection{C11 C atom ADPs}

In phase III the refined $U_{\text {eq }}$ values for the C atoms in C11 chains change almost linearly upon cooling and were fitted by a first-order polynomial $U_{\text {eq }}(\mathrm{T})=u T+v$, where $u$ and $v$ are arbitrary coefficients. Fig. 8 shows the inclination coefficient $u$ for each carbon. The $u$ coefficients for the atoms in the middle of the chain ( $\mathrm{C} 5 a / \mathrm{C} 6 a$ and $\mathrm{C} 5 b / \mathrm{C} 6 b)$ are notably bigger than for the extreme ones $(\mathrm{C} 1 a / \mathrm{C} b a$ and $\mathrm{C} 1 b / \mathrm{C} b b)$. Consequently, the ADPs for the terminal $\mathrm{C} 1 a / \mathrm{C} b a$ and $\mathrm{C} 1 b / \mathrm{C} b b$ atoms are less affected by cooling than the ADPs for C5a/C6 $a$ and $\mathrm{C} 5 b$ / $\mathrm{C} 6 b$. In other words, the terminal chain $\mathrm{C}$ atoms behave like nodes and the central ones are the most susceptible to molecular vibrations. This probably indicates that the contribution of the internal modes for the ADPs in C11 chains is more relevant than any distortion caused by the relative movement between the C11 and HMT molecules.

\subsection{O atom PDFs}

In order to understand the nature of the disorder observed in the $\mathrm{O} 2 a, b$ and $\mathrm{O} 4 a, b$ atoms, an analysis of the anharmonicity as a function of the temperature has been undertaken. For the sake of consistency and direct numeric comparison, thirdorder anharmonic displacement parameters were refined for all eight independent $\mathrm{O}$ atoms in the structure. The most temperature-dependent $C_{i j k}$ coefficients for each $\mathrm{O}$ atom $(l)$ were determined by calculating the following quantities: $\delta^{l}=$ $\left[\chi_{1}^{l}-\chi_{2}^{l}\right]$, where $\chi_{1}^{l}=C_{i j k}(293 \mathrm{~K})$ and $\chi_{2}^{l}=C_{i j k}(93 \mathrm{~K})$. As can be seen in the Fig. 9, the $C_{i j k}$ coefficients related to $\mathrm{O} 4 a$ and $\mathrm{O} 4 b$ atoms change particularly upon cooling. Additionally all 
the $C_{i j k}$ coefficients shown in Fig. 9 depend on $T^{2}$, as expected for a truly anharmonic disorder.

In order to determine whether the $\mathrm{O} 4 a$ and $\mathrm{O} 4 b$ anharmonicity is caused by constraints, the relative displacements of their neighbours has also been investigated. The distances to atoms in the first three coordination shells around $\mathrm{O} 4 a$ and $\mathrm{O} 4 b$ at 93 and $293 \mathrm{~K}$ are indicated in Table 4. The major shifts observed around $\mathrm{O} 4 a$ occur in the positions of the $\mathrm{H}$ atoms $\mathrm{H} b^{\mathrm{i}}, \quad \mathrm{H} e a b^{\mathrm{i}}$ and $\mathrm{Heab}{ }^{\mathrm{ii}} \quad$ [(i) $1+x, \frac{3}{2}-y, \frac{1}{2}+z$, (ii) $\left.x, \frac{3}{2}-y, \frac{1}{2}+z\right]$, all belonging to the third coordination shell. All these $\mathrm{H}$ atoms are linked to the $\mathrm{C}$ atoms of HMT. The $\mathrm{O} 4 a$ PDFs at different temperatures (Fig. 10a) show a persistent elongation in a direction roughly perpendicular to the $\mathrm{O} 4 a-$ $\mathrm{Cba}$ bond direction, despite the overall reduction of the displacement parameters. No significant change in the PDF was observed in the $\mathrm{O} 4 a-\mathrm{H}$ directions. It is likely that from RT down to $93 \mathrm{~K}$ the $\mathrm{O} 4 a$ atom experiences the same form of anharmonic potential. The O4b PDFs at different temperatures are shown in Fig. 10(b). The major shifts observed around $\mathrm{O} 4 b$ occur in the positions of the $\mathrm{H}$ atoms $\mathrm{H} f b a, \mathrm{H} h b a^{\mathrm{i}}$ and $\mathrm{H} 8 b b^{\text {ii }}$ [(i) $1+x, y, z$; (ii) $\left.-1+x, y, z\right]$. $\mathrm{H} f b a$ belongs to the second coordination shell and the others to the third coordination shell around $\mathrm{O} 4 b . \mathrm{H} 8 b b^{\mathrm{ii}}$ is linked to a carbon in an acid chain and the others belong to an HMT molecule. The potential curves at $293 \mathrm{~K}$ in the $\mathrm{O} 4 b m-\mathrm{H} h b a^{i}$ and $\mathrm{O} 4 b m-$ $\mathrm{H} 8 b b^{\text {ii }}$ directions do not deviate significantly from harmonicity up to distances $1.1 \AA$ from the $\mathrm{O} 4 b$ atom. In the potential around the $\mathrm{O} 4 a$ atom the deviation from the harmonic limit could already be detected at $0.65 \AA$ from the equilibrium position at $293 \mathrm{~K}$. At $93 \mathrm{~K}$ no significant anharmonicity was observed in the potential curves in the $\mathrm{O} 4 b m-\mathrm{H} h b a^{\mathrm{i}}$ and $\mathrm{O} 4 b m-\mathrm{H} 8 b b^{\mathrm{ii}}$ directions. Thus, the movement of atoms $\mathrm{H} h b a^{\mathrm{i}}$ and $\mathrm{H} 8 b b^{\mathrm{ii}}$ (those moving most upon cooling) also does not seem to influence the potential around $\mathrm{O} 4 b$.

\section{Conclusions}

HMT and C11 molecules form co-crystals in which the packing is mainly determined by strong hydrogen bonds between the $\mathrm{O}-\mathrm{H} \cdots \mathrm{N}$ bonds $(\mathrm{O}$ atoms belonging to the undecanedioic acids and $\mathrm{N}$ atoms belonging to the HMT). From the melting point down to liquid nitrogen temperature three distinct phases were observed. The high-temperature phase I is not crystalline and was not studied in the present work. Phase II is disordered, its average structure can be described in space group Bmmb. In this phase the HMT molecules are interconnected by $\mathrm{C} 11$ chains with two symmetry-related orientations. The disorder of the $\mathrm{O}$ atoms in the carboxylic group is complex and cannot be entirely described by atom splitting. However, due to the limited data quality, no further investigation could be performed. Phase III of HMT-C11 is partially disordered and described in space group $P 2_{1} / c$. In this phase the asymmetric unit is composed of two HMT-C11 units. The analysis of structure evolution within phase III upon cooling revealed that HMT molecules and C11 chains behave like rigid bodies, i.e. intramolecular distances and angles are almost invariant. The $\mathrm{O}$ atoms not participating in the hydrogen bonds linking HMT to $\mathrm{C} 11$ chains $(\mathrm{O} 2 a, b$ and $\mathrm{O} 4 a, b)$ are dynamically disordered (anharmonicity). The anharmonicity in the $\mathrm{O} 4 a, b$ atoms displacements is more remarkable than in the $\mathrm{O} 2 a, b$ atoms, but at least down to $93 \mathrm{~K}$ it does not seem to be directly influenced by the movements of the nearby $\mathrm{H}$ atoms.

The main structural change observed in phase III upon cooling was the increase in the tilt angle of the chains and a rotation of the HMT molecules. The observed angular tilt between the chains is directly correlated with the displacement of the HMT cages. Thus, the $\mathrm{C} 11$ chain would follow HMT (or vice versa) owing to the strength of the $\mathrm{O}-\mathrm{H} \cdots \mathrm{N}$ bonds. In phase III the $\mathrm{O}-\mathrm{H} \cdots \mathrm{N}$ distance is almost invariant while the $\mathrm{O}-\mathrm{H}$ distance decreases and $\mathrm{H} \cdots \mathrm{N}$ increases systematically upon cooling. Nevertheless, the refinements performed so far indicate that only the $\mathrm{O}-\mathrm{H} \cdots \mathrm{N}$ type of hydrogen bond links the HMT molecules to the $\mathrm{C} 11$ chains.

This work was supported by the Swiss National Science Foundation grant 20.56870.99. We thank Dr Vaclav Petříček V for help with the JANA2000 program. We also acknowledge Dr Kurt Schenk, Dr Marc Hostettler and Dr Andreas Schönleber for the helpful discussions and critical reading of this manuscript. MG is grateful to the Swiss National Science Foundation for the one year grant in Vienna.

\section{References}

Bachmann, R. \& Schulz, H. (1984). Acta Cryst. A40, 668-675.

Bond, A. D., Edwards, M. R. \& Jones, W. (2001a). Acta Cryst. E57, o143-o144.

Bond, A. D., Edwards, M. R. \& Jones, W. (2001b). Acta Cryst. E57, o141-o142.

Bonin, M., Welberrry, R., Hostettler, M., Gardon, M., Birkedal, H., Chapuis, G., Möckli, P., Ogle, A. C. \& Schenk, J. K. (2003). Acta Cryst. B59, 72-86.

Bürgi, H. B., Capelli, S. C. \& Birkedal, H. (2000). Acta Cryst. A56, 425-435.

Bussien Gaillard, V., Chapuis, G., Dusek, M. \& Petrícek, V. (1998). Acta Cryst. A54, 31-43.

Bussien Gaillard, V., Paciorek, W., Schenk, K. \& Chapuis, G. (1996). Acta Cryst. B52, 1036-1047.

Dickinson, R. G. \& Raymond, A. L. J. (1923). Am. Chem. Soc. 45, 22 29.

Dupré la Tour, F. (1932). C. R. Acad. Sci. Paris, pp. 622-622.

Gao, Q., Weber, H.-P. \& Craven, B. M. (1994). Acta Cryst. B50, 695703.

Gardon, M., Pinheiro, C. B. \& Chapuis, G. (2003). Submitted for publication.

Gardon, M., Schenk, K. J., Bonin, M. \& Tolèdano, P. (2003). Submitted for publication.

Gardon, M., Schönleber, A., Chapuis, G., Hostettler, M. \& Bonin, M. (2001). Acta Cryst. C57, 936-938.

Haget, Y., Cuevas, M. A., Chanh, N. B., Bonpunt, L. \& Font Altaba, M. (1980). J. Appl. Cryst. 13, 93-95.

Hostettler, M., Birkedal, H., Gardon, M., Chapuis, G., Schwarzenbach, D. \& Bonin, M. (1999). Acta Cryst. B55, 448-458.

Housty, J. (1968). Acta Cryst. B24, 486-494.

Housty, J. \& Hospital, M. (1964). Acta Cryst. 17, 1387-1390.

Housty, J. \& Hospital, M. (1965a). Acta Cryst. 18, 693-697.

Housty, J. \& Hospital, M. (1965b). Acta Cryst. 18, 753-755.

Housty, J. \& Hospital, M. (1966a). Acta Cryst. 20, 325-329.

Housty, J. \& Hospital, M. (1966b). Acta Cryst. 21, 553-559. 


\section{research papers}

Housty, J. \& Hospital, M. (1966c). Acta Cryst. 21, 29-34.

Housty, J. \& Hospital, M. (1967). Acta Cryst. 22, 288-295.

Johnson, C. K. (1970a). Crystallographic Computing, edited by F. R. Ahmed, pp. 207-220. Copenhagen: Munksgaard.

Johnson, C. K. (1970b). Crystallographic Computing, edited by F. R. Ahmed, pp. 220-226. Copenhagen: Munksgaard.

Johnson, C. K. \& Levy, H. A. (1974). International Tables for X-ray Crystallography, Vol. IV, pp. 311-336. Birmingham: Kynoch Press. (Present distributor: Kluwer Academic Publishers, Dordrecht.)

Kampermann, S. P., Sabine, T. M., Cravens, B. M. \& McMullan, R. K. (1995). Acta Cryst. A51, 489-497.

Kay, M. I. \& Katz, L. (1958). Acta Cryst. 11, 289-294.

Kuhs, W. F. (1992). Acta Cryst. A48, 80-98.

Li, W., Zhang, J. P., Tong, M. L. \& Chen, X. M. (2001). Aust. J. Chem. 54, 213-217.

Molecular Simulations Inc. (1997). Cerius2. Molecular Simulations Inc., New York. http://www.accelrys.com/about/msi.html.
Oxford Cryosystems (1997). Oxford Cryosystems, Oxford, England. http://www.oxfordcryosystems.co.uk.

Oxford Diffraction (2001). Xcalibur, Version 1.167. Oxford Diffraction, Wroclaw, Poland. http://www.oxford-diffraction.com.

Petříček, V. \& Dušek, M. (2000). JANA2000. Institute of Physics of the Academy of Science of the Czech Republic, Prague, Czech Republic.

Sheldrick, G. M. \& Schneider, T. R. (1997). Methods Enzymol. 277, 319-343.

Siemens (1998). SHELXTL, Version 5.0. Siemens Energy \& Automation, Inc. Analytical Instrumentation, Madison, Wisconsin, USA.

Sintes, A., Housty, J. \& Hospital, M. (1966). Acta Cryst. 21, 965970.

Stoe (1997). IPDS Software Manual, Version 2.87. Stoe and Cie GmbH, Darmstadt, Germany. http://www.stoe.com.

Terpstra, M., Craven, B. M. \& Stewart, R. F. (1993). Acta Cryst. A49, 685-692. 